IFN Working Paper No. 1105, 2016

Seniority Rules, Worker Mobility and Wages: Evidence from Multi-Country Linked EmployerEmployee Data

Petri Böckerman, Per Skedinger and Roope Uusitalo 


\title{
Seniority Rules, Worker Mobility and Wages: Evidence from Multi-Country Linked Employer-Employee Data*
}

Petri Böckerman, Turku School of Economics, Labour Institute for Economic Research, Helsinki and IZA, Bonn.

E-mail: petri.bockerman@labour.fi

Per Skedinger, Research Institute of Industrial Economics, Stockholm, and Centre for Labour Market and Discrimination Studies, Linnaeus University, Växjö.

E-mail: per.skedinger@ifn.se

Roope Uusitalo, Jyväskylä University School of Business and Economics.

E-mail: roope.h.uusitalo@jyu.fi

January 8, 2016

\begin{abstract}
We construct a multi-country employer-employee data to examine the consequences of employment protection. We identify the effects by comparing worker exit rates between units of the same firm that operate in two countries that have different seniority rules. The results show that last-in-first-out rules reduce dismissals of older, more senior workers, especially in shrinking multinational firms, and increase their bargaining power, resulting in a steeper seniority-wage profile.
\end{abstract}

Keywords: Multi-country linked employer-employee data, Employment protection legislation, Seniority rules

JEL codes: K310, J630, J320, J080, L510

* This research project is funded by the Finnish Work Environment Fund. The second author also thanks the Johan and Jakob Söderberg Foundation for financial support. We are grateful to Eija Ahopelto, Auli Jaakkola, Eija Savaja for their help with the Finnish payroll record data and to Malin Olsson Tallås and Olga Pugatsova for assistance with the Swedish data. We also thank seminar participants at EALE, IFN, VATT, SSB, GAPE, PT, Linnaeus University and the Nordic Summer Institute for their comments. 


\section{Introduction}

Despite considerable amount of research, the effects of job protections are still controversial. Economic theory predicts that tighter regulation decreases both the hiring and firing rates, while the effects on employment are ambiguous. Tighter employment protection legislation (EPL) may also strengthen the position of insiders and have harmful effects on new entrants. Employment protection may also affect wages, for example, by increasing the bargaining power of better-protected workers.

Empirical studies summarized in Skedinger (2010a) and in Boeri and Van Ours (2013) generally confirm the predictions regarding the effects on labor flows, but the effect on aggregate employment varies across studies. There is only scant evidence on the effects on wages with some studies reporting positive (e.g., van der Wiel, 2010) and some negative effects (e.g., Leonardi and Pica, 2013)

We contribute to the empirical literature by examining the effects of labor market regulations based on longitudinal multi-country employer-employee data. To the best of our knowledge, this is the first effort linking personnel data for a large number of firms across national borders. We merge the complete payroll records of 150 firms that operate in both Sweden and Finland. These data allow us to observe the changes in employment status at the individual worker level in the matched firms over the period 2000-2011 to compare seniority wage profiles across units of the same firm operating under different employment protection laws.

The Swedish and Finnish units of the firms that are included in our linked data operate under similar macroeconomic conditions but face different labor market regulations. The Swedish and Finnish economies are comparable with respect to aggregate unemployment, GDP per capita, general education level, union density, the fraction of workers with temporary jobs, and industry structure. As both countries are export-oriented small economies selling largely to the same markets, even the timing of the business cycle has coincided in the two countries. Both Sweden and Finland experienced robust economic growth in the early 2000s and then faced a severe aggregate contraction in 2008. 
Focusing on the same firms makes the operating environment of the units in different countries even more similar. The units of the same firm generally use similar production technology and often sell identical products, although (with the exception of exporting firms) to different markets. These multinational firms are also likely to have a uniform corporate culture, common personnel policies, similar job titles and the same general leadership.

The crucial difference between units located in different countries is that the units operating in Finland are subject to Finnish labor law and the units operating in Sweden are subject to Swedish law. Overall, the two countries' rules related to EPL are not very different. However, the aggregate indices mask important differences in details. In this paper, we concentrate on the effects of seniority rules that differ markedly across these two countries. In Sweden, firms must in principle follow a strict last-in-first-out policy, while such regulations do not exist in Finnish labor law. Seniority rules may affect average dismissal costs and certainly should affect the choice of workers who are fired when a firm downsizes. We are particularly interested in how these rules affect the layoff risks and wages in different age groups.

Our research design exploiting within-firm cross-country variation is most directly comparable to a recent study by Lafontaine and Sivadasan (2009), who examine the effects of labor market rigidities using data on employment and sales from a single US-based international fast-food chain that operates in 43 countries. Compared to their study, our twocountry study has much less variation in employment protection. However, focusing on two rather similar countries makes the operating environments much more similar in several other dimensions that affect employment than in a 43-country comparison. Similar to Lafontaine and Sivadasan (2009), we also examine differences within firms across countries, thus effectively controlling for differences in production technology, product type and firmspecific personnel policies. The firms in our data operate in diverse industries, ranging from retail sales to manufacturing, and hence our approach yields more generalizable results than those obtained from a single firm that operates in a very specific market. Importantly, having individual-level data on all employees in the linked firms allows us to examine worker mobility and wages disaggregated by age and tenure, thereby providing reliable evidence on the heterogeneous effects of seniority rules in these important dimensions.

Our findings regarding the effects of seniority rules should also be of interest outside the Nordic context. In addition to in Sweden, seniority rules are part of EPL in several countries, 
although their weight relative to other selection criteria varies. In many countries, including the United States, collective agreements contain seniority rules.

The paper is structured as follows. Section 2 summarizes the key aspects of the literature. Section 3 describes the context of our two-country study focusing on the differences in seniority rules and the similarity of the economies. Section 4 introduces the linked multicountry employer-employee data. Section 5 reports on the empirical analyses. Section 6 concludes.

\section{Literature}

\subsection{Effects on worker mobility}

The vast majority of the early empirical studies on the effects of labor market regulations on labor market flows were based on cross-country comparisons. These studies used indices of the tightness of employment protection rules and related these indices to aggregate measures of labor market performance (e.g., Lazear, 1990; Nickell and Layard, 1999). More recently, the focus has shifted to a more disaggregated level, enabling separate analysis and more nuanced estimates for specific sub-groups defined by gender, age, firm or industry (e.g., Burgess et al., 2000; Haltiwanger et al., 2006; Kahn, 2007; Messina and Vallanti, 2007). However, a major problem in all cross-country studies is that differences in labor market performance may be due to country-specific factors other than the strictness of EPL. Even with panel data, identification is difficult because institutions tend to change slowly. Another limitation is that cross-country comparisons typically rely on rather coarse measures of job protection and therefore miss the effects of institutional details that are important for policy design.

Causal inference on the effects of job protection legislation is more straightforward in withincountry studies. A wave of empirical studies have used data from 'natural experiments' exploiting settings in which the changes in employment protection rules affect only some workers - for example workers in firms below some size threshold. An example of this strand of research, most closely related to our paper, is a Swedish study by von Below and Skogman-Thoursie (2010), who evaluate the effect of relaxing last-in-first-out rules in small firms. Natural experiment approaches and within-country data have also been used by, e.g., 
Autor et al. (2007), Boeri and Jimeno (2005), Kugler (2004), Kugler and Pica (2008), and Martins (2009). While analyzing the effects of reforms within countries may be useful in obtaining causal effects, these studies suffer from an inability to capture economy-wide, general equilibrium effects, for example, through changes in wages. Reforms of EPL affecting only some workers may have also had an impact on the comparison groups in the analysis, which impairs causal interpretation of the treatment-control differences.

A general problem affecting both cross- and within-country studies is that EPL may be endogenous. High unemployment increases the demand for better job protection, and hence tighter rules may be a result of high unemployment rather than its cause. Additionally, the targeted policy reforms that have been analyzed in the literature are problematic because the explicit aim of these reforms has often been to alleviate unemployment in the targeted groups. High layoff risks and associated costs in specific groups (e.g., older workers) may have induced policy makers to create better job protections for these groups, or difficulties in finding jobs in some groups (e.g., the young) may have resulted in policies that reduced hiring risk by relaxing employment protection rules applicable to these specific groups. Both of these mechanisms could lead to reverse causality and biased estimates concerning the effect of EPL on labor market outcomes.

\subsection{Effects on wages}

As shown by Lazear (1990), income transfers from firms to workers, induced by EPL, can in principle be neutralized by wage reductions for newly hired workers. The extent to which such wage reductions actually occur is likely to be dependent on the specific institutional framework in which the labor markets operate. Minimum wages, collective labor agreements and social norms may hinder or slow the adjustment to lower wages, especially at the bottom of the wage distribution and among blue-collar workers, as Lindbeck and Snower (2001) argue.

Some prior evidence indicates that increased employment protection for workers on openended contracts has differential impacts on wages, depending on the bargaining power of the group concerned. Analyzing an Italian reform in 1990, Leonardi and Pica (2013) find that entry wages were reduced as the stringency of employment protection increased, while 
incumbents remained unaffected. According to van der Wiel (2010), longer periods of advance notice before a dismissal contribute to higher wages among Dutch workers. Similarly, Centeno and Novo (2014) report that the new cohorts with open-ended and fixedterm contracts were those who ultimately paid for additional employment protection for incumbent workers with permanent contracts in Portugal in 2004.

To the best of our knowledge, there is no previous empirical research on the impact of seniority rules on wages. Arguably, such rules, which do not apply to workers on fixed-term contracts, will strengthen the bargaining power of long-tenured workers relative to those with short tenures or with fixed-term contracts. Assuming that productivity increases with tenure in a similar fashion for comparable workers in the Swedish and Finnish units of multinational firms, our prior would then be that seniority-wage profiles are significantly steeper in Sweden. Because union-bargained minimum wages are more binding in Sweden than in Finland, it remains an open question whether our prior will be consistent with the empirical facts.

There are also other relevant theoretical explanations that can characterize the potential effects of seniority rules on wages. According to standard learning models (see, e.g., Jovanovic, 1979), employers gradually accumulate more precise information about their employees, implying that the better-matched workers become less likely to leave the firm over time. The existence of compensating wage differentials would imply that wages are, in equilibrium, lower for the better-protected older workers. However, this argument is not time consistent in the sense that there is an incentive for a worker to renegotiate his/her wage after the contract has been signed. Alternatively, seniority rules can be interpreted as a commitment device for the enforcement of implicit contracts. According to this theoretical reasoning, employees' wage profiles in the firm are increasing (Lazear, 1979). The model implies that new employees are underpaid relative to their marginal productivity, i.e., their wage is lower than their productivity. This positive difference between a worker's productivity and wage is held by the firm in the form of a 'bond'. The difference is paid to the worker in later years if the worker remains employed with the same firm. Thus, senior employees are overpaid, i.e., their wage exceeds their marginal productivity at the end of the working career in the firm. The increasing wage profile solves the incentive problem of providing efficient effort because the worker loses the bond if he quits or is fired from the firm. The firm retains these implicit 
contracts to maintain its reputation. From this perspective, seniority rules can be regarded as an explicit labor market rule that supports employers’ commitment to implicit contracts.

\section{Context}

\subsection{Employment protection legislation and seniority rules}

In both Sweden and Finland, the basic rules regarding employment protection are stated in the labor law. These laws determine the procedures that need to be followed when firms dismiss workers. Dismissals for personal misconduct are possible in both countries, but by far the most common reasons for dismissals are ‘economic and production related reasons'. For example, the Finnish labor law states that a firm may dismiss a worker when available work has 'significantly and permanently reduced', while the Swedish law stipulates that a 'lack of work' may be sufficient reason for dismissal. The labor laws establish minimum requirements for an advance notice period that increase with seniority in both countries. Compensation for unfair dismissal is more generous to long-tenured workers in Sweden (for example, 32 monthly salaries for workers with 20 years' tenure, as opposed to 14 in Finland). Discrimination based on gender, age or ethnic origin is prohibited, and some groups of workers, such as employee representatives, pregnant women, those on parental leave, and those who have lost part of their work ability while working for the same employer, are better protected. According to the most recent OECD summary indicators for 2013, job protection for regular workers is slightly tighter in Sweden than in Finland, while the regulation of temporary contracts is somewhat more lenient in Sweden.

In addition to such legislation, most firms in both countries have to follow collective agreements. The union contracts are binding irrespective of whether the individual worker is a union member. ${ }^{1}$ The union contracts typically extend the minimum requirements stated in the law, for example, by increasing the advance notice periods.

The crucial difference in the EPL concerns last-in-first-out-rules. These seniority rules have been included in Swedish legislation since 1974. The basic rule states that workers have to be

\footnotetext{
${ }^{1}$ In Sweden, the contracts are binding only if the employer belongs to an employer association or has signed a local collective agreement ('hängavtal'), whereas in Finland, contracts may also be binding for non-member firms if the collective agreement has been legally extended to cover such employers.
} 
laid off in inverse order of seniority when a firm downsizes for economic reasons. For workers with equal seniority, the youngest worker is laid off first. Such rules do not exist in Finnish labor law.

In practice, the differences between the two countries are somewhat smaller. The Swedish legislation on last-in-first-out rules specifies the group of workers and workplace units for which the rankings apply ('turordningskrets'). In addition to the establishment as the basic unit for the ranking of workers, it is usually the case that separate rankings apply depending on negotiation area, implying that blue- and white-collar workers are treated as separate groups. The legislation also allows some latitude for the competence of the worker to be a factor when determining the relevant group of workers. The more narrowly defined the group is, the larger is the scope for the employer to retain the most valuable employees. Additionally, an important feature of Swedish legislation is the possibility to depart from lastin-first-out rules, in local agreements ('avtalsturlista') between employers and unions, as long as the agreements are not discriminatory or otherwise improper. There is scant documentation of these agreements, and they are not recorded in our data. A survey of representatives of employers and unions in 200 firms that had to reduce production during the last two years indicates that local agreements were made in $50 \%$ of cases of downsizing for white-collar workers but that these agreements were rare occurrences for blue-collar workers (Confederation of Swedish Enterprise, 2012; Larsson et al., 2013). Thus, strict adherence to the last-in-first-out rules is more prevalent when dismissing blue-collar workers, and some of their unions have also adopted a policy of approving local agreements only in exceptional cases.

As mentioned above, Finnish labor law does not contain any reference to the layoff order. However, some union contracts, for example the contract for the engineering industry, contain a supplement with regulations on how to choose which workers to lay off when the firm downsizes. By contrast, the collective agreements in, for example, retail trade or hotels and restaurants contain no clauses on the layoff order. Even in engineering, the employer has a right to retain key workers who are 'crucial for the production process'. Other valid selection criteria include competency in, for example, operating specific machines. Only after mentioning these criteria does the contract list tenure in the firm and the number of dependent children as possible additional factors that should affect the choice of which workers to fire. There are some cases in the Labor Court in which the employer has been found guilty of 
breaking the contract, but in these cases, the employer fired a worker with a tenure of over 20 years while retaining a less competent worker with a much shorter tenure. Even in these cases, the fines have been rather small, between $€ 2000$ and 4000 .

Seniority rules are part of a wider concept in EPL, namely right-to-priority (RTP) rules. RTP defines criteria according to which employees should be prioritized in the event of dismissals for economic reasons. A number of countries incorporate RTP rules in their legislation (see, e.g., Bergström, 2011, for an extensive discussion and World Bank, 2015), but very few explicitly refer to seniority as the exclusive or main criterion. In addition to Sweden, such countries include India and the Netherlands, and the details specifying how seniority should be taken into account differ somewhat among them. RTP rules in other countries, e.g., Austria, China, France, Germany and Spain, do not emphasize seniority at all or only to a limited extent. Other factors, such as the number of dependents, disability, age or status as a union representative, should be given all or equal weight relative to seniority. However, another group of countries, including Belgium, Denmark, Finland, Norway, the United Kingdom and the United States, implement no RTP rules whatsoever in their EPL. Instead, legislation is limited to defining what constitutes 'unfair' grounds for dismissal (which is also included in legislation in countries with RTP rules). Thus, discrimination on the basis of ethnicity, gender, sexual orientation, etc., is prohibited, and certain personal circumstances, such as pregnancy, parental leave and military service, should not be cause for dismissal.

\subsection{Stylized features of the Swedish and Finnish economies}

Both Sweden and Finland are small open economies and members of the European Union. Finland is the smaller of the two with a population of 5.1 million, while Sweden has 9.6 million inhabitants. The countries are located on either side of the Gulf of Bothnia, and they were part of the same nation for centuries until the Swedish-Russian war of 1809. The economic and cultural ties between these two Nordic countries are tight. Approximately 5\% of Finns speak Swedish as their native tongue, and approximately 5\% of Swedes are first- or second-generation immigrants from Finland.

The macroeconomic cycles were nearly identical in Sweden and Finland over the period 1999-2011. This pattern is plainly shown in the indicators of change in GDP, export growth 
and the fluctuations of aggregate domestic demand (Figure 1). Similar macroeconomic conditions are naturally reflected in the key labor market indicators such as employment growth.

Figure 1. Macroeconomic indicators in Finland and Sweden.
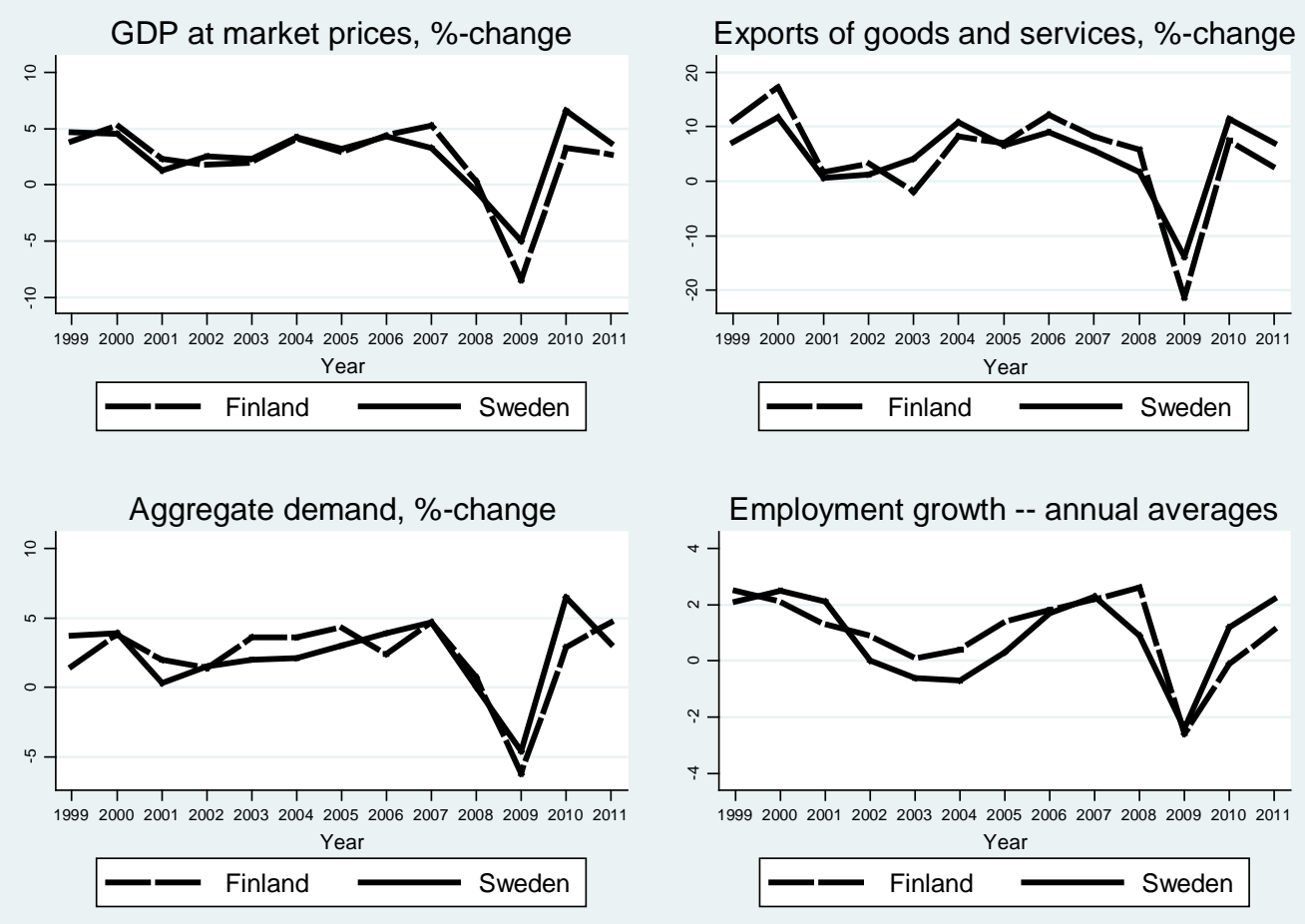

Source: Eurostat.

Both Sweden and Finland are export-oriented small economies and heavily dependent on the demand conditions in their primary export markets in Europe, the US and Asia. Business cycle fluctuations in both countries are therefore usually due to changes in export demand. The fact that Sweden retains its own currency while Finland is part of the Economic and Monetary Union has not changed this situation. In fact, the exchange rate between the Swedish krona and euro was quite stable during the observation period, except for a brief period with a temporarily weaker Swedish krona in 2009. In particular, the evolution of the Swedish and Finnish economies in the aftermath of the global financial crisis that began in 2008 was similar. The global financial crisis represented a major export shock that hit both countries, causing a drastic decline in export volume and GDP. After 2009, both countries began to recover from the shock. 
The structure of the economies is also strikingly similar on relevant dimensions. For example, the average education level of the workforce is comparable. The share of the population that has completed tertiary education among $25-34$ year-olds is close to $40 \%$ in both countries (OECD, 2013). The female labor force participation rate is high in both countries. Sweden has a slightly larger public sector and, as a result of this, a higher tax rate. According to the CESifo DICE database, ${ }^{2}$ worker mobility is also rather similar between the two countries. Most workers are hired on permanent contracts. Average tenure is slightly over 10 years in both Sweden and Finland. The share of workers with tenures of 10 years or more is $22.2 \%$ in Finland and $21.9 \%$ in Sweden. The fraction of workers with temporary contracts was $16-17 \%$ of all employed persons and 14\% for prime-age men in both countries during the early 2000s.

The countries' market institutions and wage formation also share many similar features. Wage contracts are negotiated between industry unions and employer organizations with some coordination across industries. Neither Sweden nor Finland has statutory minimum wage laws. Instead, minimum wages are determined separately in each industry in the contracts between the unions and the employer organizations. The union contracts specify a set of task-specific minimum wages that may vary by region, job-complexity level and worker experience. The union density is approximately $70 \%$ in both countries. The union contracts are extended to all workers in each firm and are therefore also binding for non-union workers with few exceptions. The coverage of collective labor agreements is consequently close to $90 \%$ in both countries.

Employees are generally well insured against income losses. Sweden and Finland both have earnings-related unemployment insurance. The replacement rate is dependent on preunemployment earnings and is relatively similar in these countries. For example, the net replacement rate for those who have been unemployed for six months was $64 \%$ of preemployment earnings in Finland and 69\% in Sweden in 2009. Earnings-related unemployment insurance is based on voluntary membership in mostly union-run unemployment insurance funds. This system, whereby the unions administer governmentsubsidized unemployment insurance funds, is known as the Ghent system. Both countries also have earnings-related pensions and guaranteed minimum pensions. The expected effective

\footnotetext{
${ }^{2}$ http://www.cesifo-group.de/ifoHome/facts/DICE.html
} 
retirement age for 50-year-olds is a few years higher in Sweden than in Finland. Early retirement schemes in Finland are mostly relevant for those who are aged 60 or over (Tuominen, 2013).

\section{Data}

Our primary data originate from the payroll records of the Swedish and Finnish central employers’ organizations. Employers' organizational structures in Sweden and Finland are quite similar, with a large central federation in both countries that is composed of several industry-wide member organizations. ${ }^{3}$ The central federation in each country maintains the payroll records, but access to the data is more cumbersome in Sweden because not only the central federation but also each member organization has to approve access to data on their member firms. We gained access to data from three large industries: engineering, retail trade, and hotels and restaurants. For Finland, our data contain the entire private sector. Originally, the Finnish data for the hourly paid blue-collar and monthly paid white-collar workers were collected separately, but we have included both in the data linked to Swedish firms.

The payroll record data cover all workers in all firms that are members of the employers' organizations in the respective countries. Nearly all large firms are members of the employers' organizations, but not all small firms are included. On the one hand, this implies that the data provided by the employers' organizations are not representative of the overall economy. On the other hand, nearly all large multinational firms are members of the employers' organizations and hence are included in the payroll data.

Information in the payroll data comes directly from the firms' pay systems. These data were originally gathered to monitor wage growth after a union contract has been agreed upon, and consequently, they are used as a basis for ongoing negotiations over collective labor agreements. The statistical authorities also use these data to construct official measures of earnings growth. Thus, these data are highly accurate and contain minimal measurement error that is common in wage surveys. These data have been frequently used in research both in

\footnotetext{
${ }^{3}$ Finland formerly had two different employer federations that merged in 2005. Currently, most large employers belong to the Confederation of Finnish Industries (EK) that is also the organization that kindly provided us with data on both its members and on the members of the previous employer organizations.
} 
Sweden and in Finland but thus far always in anonymized form whereby person and firm identifiers are removed such that individual firms and workers cannot be identified from data. For our specific linking purposes, it was necessary to obtain the true firm IDs and firm names for which we obtained permission from the respective employer organizations in both countries.

The payroll data contain records on each worker employed by the member firms at the end of each year, and they can be used to calculate various measures of employment in firms. They also contain a large amount of useful information on the individual workers, including age, gender, wage, working hours, occupation, pay period, collective agreement and, in Finland, tenure in the firm.

Payroll data in both Sweden and Finland contain unique identifiers for both firms and workers that are consistent over time. For this study, we use data covering the period 2000-2011. A wide time range is particularly important for the analyses of the effects of seniority rules on worker mobility, as the data cover a full business cycle from peak to trough in both countries. For the identification of the effects, it is also useful that the data period captures the recent global financial crisis that caused a major exogenous demand shock for the firms in our data and induced them to adjust their workforce.

Using the national payroll data, we create a multi-country linked employer-employee panel. Swedish and Finnish payroll records are linked using firm names that are provided by the employers' organizations from their membership records. After the link between the national payroll record data is established, the actual names of the firms are replaced with unique anonymous identifiers that are common for those firms that operate units both in Sweden and Finland.

Specifically, we linked Swedish and Finnish payroll data using approximate string matching, based on firm-name variations. To accomplish this, we first removed any country-specific abbreviations such as Finnish and Swedish language versions of limited companies and the name extensions referring to a specific country (Sweden, Swedish, etc.). We then used probabilistic matching to match not only firms that operate under identical names but also firms that use slightly different names (often abbreviations) in the two countries. Finally, we manually checked all records and in uncertain cases checked the firms' websites to ensure that 
we were indeed capturing correct matches. We also manually verified that we included in the data all parts of the firm in cases in which the firm reports its wages separately in different units (e.g., R\&D, sales, maintenance) or in different plants. We then created a new firm ID that is shared by all units of the same firm in both countries and use this new firm ID as a definition of the firm in our empirical analyses.

Table 1 reports the number of observations for both firms and employees in the linked data for each year over the period 2000-2011. In total, we have 150 multinational firms in the linked data that operate units in both Sweden and Finland. The panel is unbalanced, not all firms are observed in all years. This is primarily due to mergers or firm entry during the observation period. The total number of firms is slightly larger in the Finnish data. Because most of the multinational firms are large as measured by number of employees, the total number of employee observations in the linked firms exceeds two million over the period 2000-2011. This gives us considerable statistical power in the individual-level models.

Table 1. The number of firms and workers in the linked data.

\begin{tabular}{lcccc}
\hline & \multicolumn{2}{c}{ Sweden } & Firms & Workers \\
\hline & Firms & Workers & & \\
\cline { 2 - 4 } 2000 & 81 & 114176 & 73 & 62145 \\
2001 & 75 & 105141 & 82 & 63815 \\
2002 & 76 & 113978 & 85 & 64738 \\
2003 & 76 & 105829 & 88 & 60125 \\
2004 & 78 & 113544 & 86 & 56105 \\
2005 & 85 & 114624 & 94 & 59295 \\
2006 & 86 & 120107 & 99 & 61789 \\
2007 & 125129 & 109 & 65786 \\
2008 & 87 & 125757 & 117 & 61864 \\
2009 & 85 & 128546 & 113 & 60507 \\
2010 & 98 & 129709 & 115 & 58270 \\
2011 & 101 & 131761 & 120 & 64262 \\
\hline N (obs) & 95 & 1428301 & 1181 & 738701 \\
\hline
\end{tabular}


The number of workers in the Swedish units is almost twice as large as that in the Finnish units (Table 1). This pattern reflects both the absolute size difference of the countries and the fact that many of the firms in the linked data are large Swedish-based multinational firms that subsequently entered the Finnish market. Additionally, many multinational firms from other countries (e.g., in the retail sector) expanded to Sweden before entering Finland because of the former's larger market size. The total number of employees in the linked Swedish firms has risen notably over the period. In contrast, in the Finnish data, there is no notable trend in the total number of employees in the linked firms.

Table 2 documents that the key employee characteristics typically do not differ substantially across the linked Finnish and Swedish units. For example, the average age of employees is comparable in the Swedish and Finnish units. However, the share of white-collar workers is larger in the Swedish units, reflecting the headquarter status of Swedish multinational firms in the linked data.

Table 2. Mean employee characteristics in the linked Finnish and Swedish firms.

\begin{tabular}{|l|l|l|}
\hline & Sweden & Finland \\
\hline & & \\
\hline Average age & 39.4 & 40.1 \\
\hline Share of males & 0.63 & 0.65 \\
\hline Share of white-collar workers & 0.52 & 0.40 \\
\hline Imputed tenure & 4.3 & 5.5 \\
\hline Average wage $(€)$ & 19.8 & 18.4 \\
\hline Usual weekly hours & 36.2 & 37.2 \\
\hline Worker exit rate & 0.21 & 0.17 \\
\hline Worker entry rate & 0.21 & 0.16 \\
\hline
\end{tabular}

Notes: Average wage is deflated to the year 2000 level using the consumer price index and converted into euros using the average exchange rate for each year. White-collar / blue-collar work is defined using occupational codes.

The final linked data set that is used in the analyses covers three major industries because of more restrictive data access policy on the Swedish side. Employment growth in the linked Swedish and Finnish units is comparable (Appendix Figure A1). The distribution of employment growth is not notably different between these countries.

The information content of the variables that are used in the analyses is standardized in our linked data. Thus, the variables are comparable in content, both across firms and industries 
within countries but also across countries. We adjusted wages to make them comparable, both in terms of reporting period and various wage components (overtime pay, Sunday bonuses, performance bonuses, etc.). We also converted all monthly wages (typically received by white-collar workers) to hourly wages using the explicit formulas from collective labor agreements.

Worker mobility measures are calculated based on changes in common firm codes in the linked data. A worker who disappears from the data while the firm is still present in the following year is classified as an exit, and a worker who appears in the data for the first time while the firm existed in the previous year is classified as a new entrant. If a worker is observed in the data in two consecutive years under different firm codes, we classify her as an exit from the first firm and an entrant in the second. As our data do not contain the entire population (the Finnish data lack the public sector and small firms; the Swedish data contain only engineering, retail trade and hotels and restaurants), we cannot reliably distinguish between job-to-job movements and entry from unemployment or exit into unemployment. Thus, we do not distinguish movements of workers between firms and out of the data. As is typical, we also cannot distinguish between layoffs and voluntary quits.

Mobility measures are corrected for artificial firm code changes that are caused by, e.g., mergers and acquisitions or ownership or name changes leading to new firm ID codes. To detect artificial code changes, we implemented identical procedures for both the Swedish and Finnish data. Our main correction procedure involves reclassifying cases in which the common firm code changes in the same way for more than $70 \%$ of the workers initially employed in the same firm.

In the empirical specifications, we use three measures for tenure: age, imputed tenure, and relative tenure within the firm (i.e., seniority). Age contains a minimal amount of measurement error because it is calculated based on personal ID codes that are available in the payroll data. For tenure and seniority, we focus on the firm level that is relevant for last-infirst-out rules. Creating comparable measures of tenure was challenging. The Finnish data contain a date of entry into the current firm that is reliable enough for calculating tenure, but such a measure does not exist in the Swedish data. 
Thus, we imputed tenure in both countries using the panel dimension of the data. We are able to follow the workers consistently in both countries back to 1995, and impute tenure based on the number of consecutive observations in the same firm. We take into account one or two year gaps in the data but having consecutive observations of the same person in the same firm. The cumulative number of gaps is added to imputed tenure. The measure of imputed tenure is also corrected for artificial firm code changes. As comparable data only extends to 1995, our tenure measures are severely censored, particularly in the earlier years of the observation period. However, for the seniority rules, the key measure is relative tenure compared to the other workers in the same firm in a given year. This can be reasonably well calculated from the data, although it is naturally impossible to distinguish between two long tenure workers. A comparison between imputed tenure and actual tenure reported in the Finnish data indicates that the imputation procedure works reasonably well. The Spearman's rank correlation coefficient for imputed and observed tenure within Finnish firms is 0.8. The correlation between imputed tenure and observed tenure is particularly strong for observed tenure up to 10 years (Appendix Figure A2). Because the measurement of seniority involves comparison to other workers in the same firm, cross-country differences in measurement are arguably less important.

\section{Results}

\subsection{Worker exits by age}

Figures 2-3 illustrate the basic patterns of the worker exit and entry rates for the linked Swedish and Finnish firms. We focus on the 1-year mobility measures using the common firm codes. Worker exit covers both worker movements from the firm to other firms included in the data and transitions out of the linked data. Similarly, worker entry also covers both entries from other firms in the data and entries to the linked data.

Figures 2-3 document the aggregate labor market flows for all workers and three specific age groups (i.e., youngest, prime-age and oldest workers) that are the most interesting for our purposes. Figure 2 reveals that the average worker exit rate for all workers was at approximately the same level in the linked Swedish and Finnish units over the period 20002010. The pattern is particularly notable at the end of the observation period. Worker exit 
rates disaggregated by worker age indicate that worker exits were the highest for the youngest workers in both countries. The level of mobility among the youngest workers is consistent with the stylized empirical facts of worker turnover. There are also some other distinct differences in the worker exit measures across age groups in Sweden and Finland. However, the use of a fully fledged regression framework is needed to pinpoint the exact differences between countries in this respect.

Figure 2. Worker exit rates by age group.

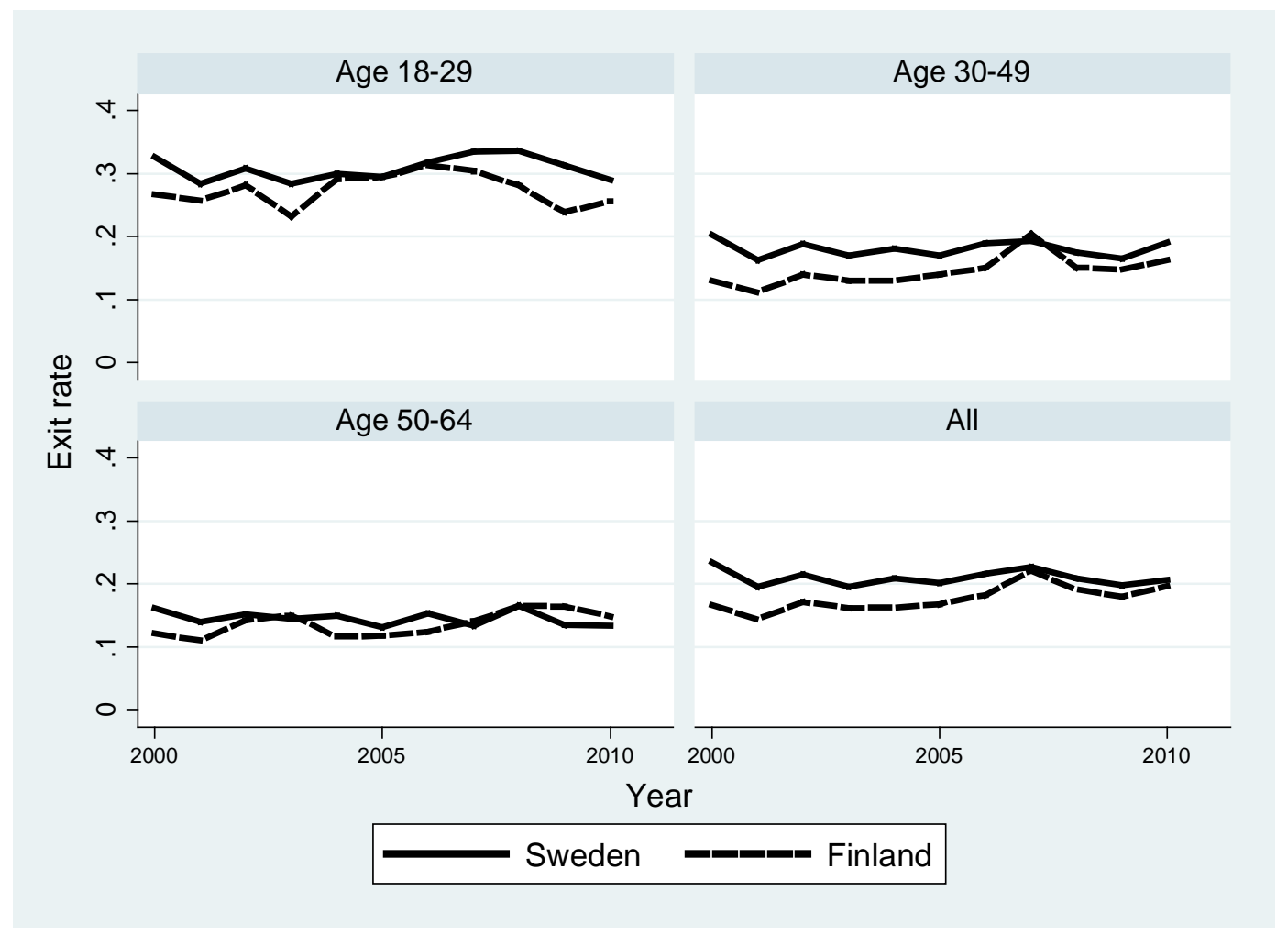

Notes: Exit rates are calculated based on firm ID changes using common firm definitions in both countries. See the text for a detailed description.

For comparison, Figure 3 shows the worker entry rates for the same age groups. The level of worker entry in the Swedish and Finnish units is comparable. Worker entry was the highest for workers aged less than 29 both in the Swedish and Finnish units of the same multinational firms. There was also a significant reduction in worker entry for the youngest workers in 2008 at the onset of the global financial crisis. Thus, a major part of the adjustment at the hiring margin occurs for the youngest workers. In contrast, for prime-age workers, we observe only a modest decline in worker entry during the crisis. 
Figure 3. Worker entry rates by age group.

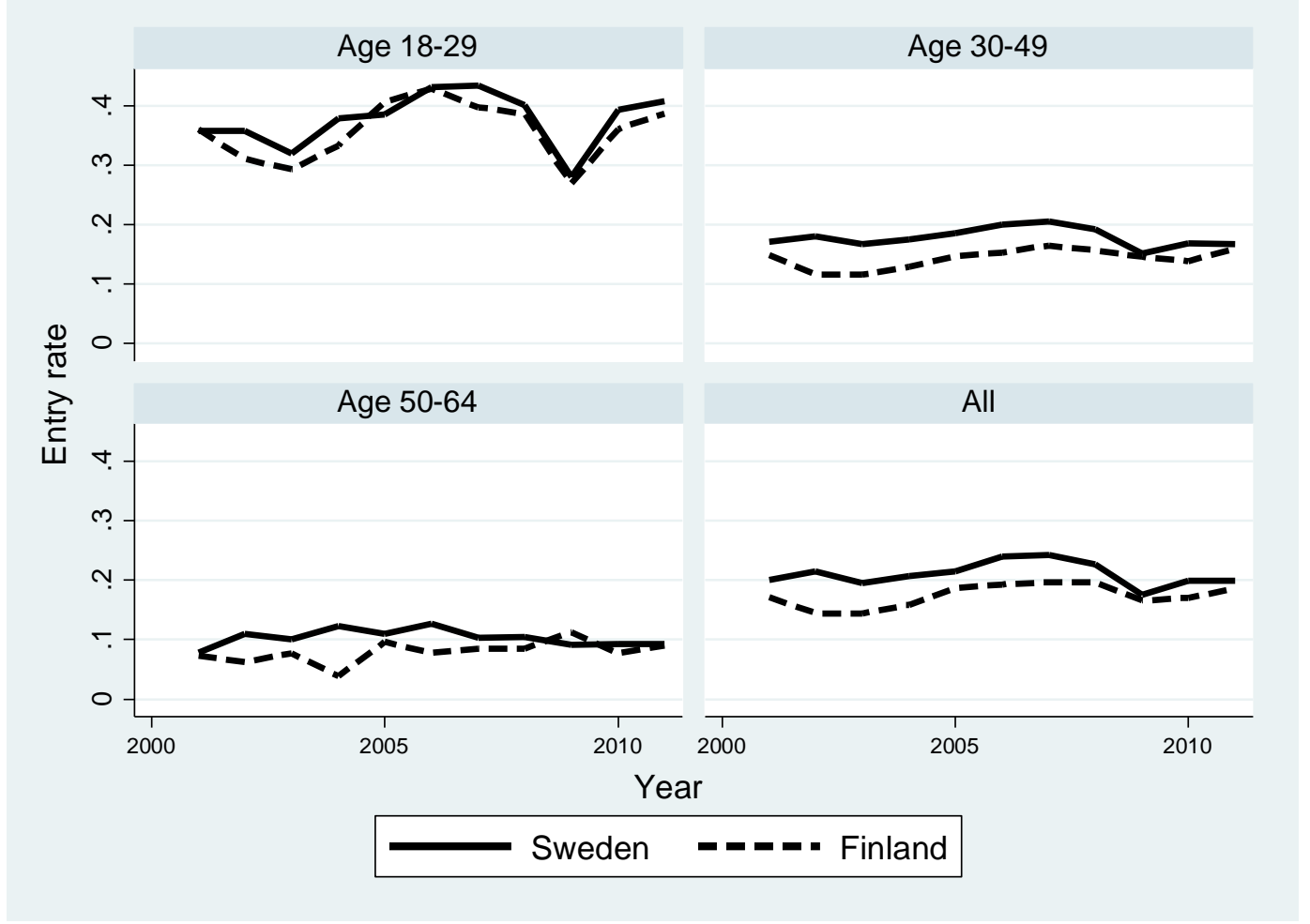

Notes: Entry rates are calculated based on firm ID changes using common firm definitions in both countries. See the text for a detailed description.

Table 3 reports the first set of estimates for the determinants of worker exit at the individual level for the linked firms. These models include a full set of indicators for three age groups (with prime-age workers as the reference group), a full set of dummy variables for the years and a country indicator for Sweden. The most interesting explanatory variables in these models are the interactions between the country indicator for Sweden and three age groups. We use Finland as the base category, and hence the estimated effects can be directly interpreted as the effects of seniority rules in the Swedish units. From Column 2 onward, the models also account for the common firm effects (i.e., firm IDs that are same for all units of the multinational firm in both countries), as indicated in the table. 
Table 3. Determinants of worker exits at the individual level.

\begin{tabular}{lcccc}
\hline & $(1)$ & $(2)$ & $(3)$ & $(4)$ \\
\hline Country indicator (Sweden) & $0.039^{* * *}$ & $0.053^{* * *}$ & $0.051^{* * *}$ & $0.030^{* * *}$ \\
& $(0.001)$ & $(0.001)$ & $(0.001)$ & $(0.001)$ \\
Age group (18-29) & & & & \\
Age group (50-64) & $0.171^{* * *}$ & $0.163^{* * *}$ & $0.163^{* * *}$ & $0.162^{* * *}$ \\
& $(0.001)$ & $(0.001)$ & $(0.001)$ & $(0.001)$ \\
& $0.011^{* * *}$ & $0.014^{* * *}$ & $0.013^{* * *}$ & $-0.008^{* * *}$ \\
Sweden $\times$ age group (18-29) & $(0.001)$ & $(0.001)$ & $(0.001)$ & $(0.001)$ \\
& & & & \\
Sweden $\times$ age group (50-64) & $-0.020^{* * *}$ & $-0.010^{* * *}$ & $-0.014^{* * *}$ & $-0.006^{* * *}$ \\
& $(0.002)$ & $(0.002)$ & $(-0.002)$ & $(0.002)$ \\
Fear effects & $(0.001)$ & $-0.028^{* * * *}$ & $-0.026^{* * *}$ & $-0.031^{* * *}$ \\
Firm effects & & $(0.001)$ & $(0.001)$ & $(0.001)$ \\
Firm by year effects & $\mathrm{X}$ & $\mathrm{X}$ & $\mathrm{X}$ & $\mathrm{X}$ \\
Excluding those who are 60+ & & $\mathrm{X}$ & $\mathrm{X}$ & $\mathrm{X}$ \\
$\mathrm{N}$ & & & $\mathrm{X}$ & $\mathrm{X}$ \\
\hline
\end{tabular}

Notes: Estimation period 2000-2010. Reference age group is 30-49. Heteroskedasticity-robust standard errors are reported in parentheses: ${ }^{* * *} \mathrm{p}<0.01,{ }^{* *} \mathrm{p}<0.05$, and ${ }^{*} \mathrm{p}<0.1$.

The specification in Column 1 of Table 3 reveals that the overall worker exit rate was approximately 4 percentage points higher in the Swedish units over the estimation period 2000-2010. The indicators for the age groups show that worker exit was highest for workers aged less than 30 compared to the reference age group consisting of prime-aged workers aged 30-49. 
The most interesting observation that emerges from Table 3 is that the difference between the exit rate in the oldest age group and the prime age group was 2.5 percentage points larger in Sweden. This interaction effect is both statistically and economically significant. The finding is consistent with the effects of the seniority rules in Sweden that significantly reduce dismissals among the oldest workers from the Swedish units of the same multinational firms.

The model in Column 2 of Table 3 adds the common firm effects to the specification using the unique feature of our linked data. Provided that firms are in the same industries in both countries, the set of firm indicators also captures prevailing industry differences. The firm effects are jointly significant at the $1 \%$ level in all models that are reported in Table 3. However, adding the firm effects have a relatively minor effect on the point estimates of interest, and their addition does not qualitatively alter the results in Column 1 . The difference in the exit rates between the oldest age group and the prime age group is 2.8 percentage points larger in Sweden. The specification in Column 3 adds a full set of year and firm interactions to the estimated model. The point estimate of interest remains essentially unchanged in this specification. $^{4}$

A potential concern for the interpretation of the estimates as the effects of the seniority rules enforced in Sweden is that the estimates for the oldest workers in Table 3 may reflect the differences in early retirement schemes between the two countries. For this reason, in Column 4, we have excluded those who are older than 60 from the estimation sample. The earlier result for the oldest age group is confirmed in this specification. In fact, the point estimate of interest is even larger in this model. Thus, we conclude from the results in Table 3 that the exit rate of the oldest employees compared to the prime age group is considerably lower in Sweden. $^{5}$

\footnotetext{
${ }^{4}$ We have also estimated a set of models that add some key individual-level controls such as gender to the vector of explanatory variables. Their addition has only a marginal effect on the point estimates of interest.

${ }^{5}$ Appendix Table A1 reports estimates for the determinants of worker entry at the firm level for the linked firms. We use the firm level in this analysis because entry cannot be consistently defined at the individual level. Observation is country-age group-firm-year cell. These estimates are weighted by firm size. The most interesting finding that emerges from these regressions is that there is no statistically significant difference in worker entry between the units that are located in Sweden vs. Finland in terms of age groups. The result remains intact when we add common firm effects (Column 2) and use the narrower estimation window that is dominated by the global financial crisis (Column 3).
} 


\subsection{Worker exits by tenure and seniority}

Table 4 reports the results when we use either imputed tenure or both imputed tenure and seniority (i.e., rank within firm) as explanatory variables. The structure of the models is similar to the results in Table 3. Because of their statistical significance, all estimated models now include the firm effects. We find that worker exit is less likely for those who have a long (imputed) tenure (Column 1). The interaction term between imputed tenure and the country indicator for Sweden shows that the effect of tenure is to reduce exits slightly more in the Swedish units (Column 1).

Column 2 adds seniority to the model. Our measure of seniority is the decile to which the worker belongs when ranked according to tenure within the firm. The estimate indicates that worker exit is substantially less likely for workers with higher seniority within a firm (Column 2). We find that those with higher seniority have a significantly lower exit probability from the Swedish units relative to the Finnish units.

In Column 3 of Table 4, we also add the age groups from Table 3 to the specification and their interactions with a country indicator for Sweden. Importantly, the earlier conclusion for the workers with higher seniority in the Swedish units of the same multinational firms remains unchanged in this specification.

Following the structure of Table 3, in Column 4 of Table 4, we estimate the specification by excluding those workers who are older than 60. The pattern remains intact. Our findings for seniority are consistent with the effects of last-in-first-out rules on the worker exit rates in Sweden. These results also support our earlier conclusion that used employee's age as a crude measure of tenure.

Table 4. Determinants of worker exits at the individual level.

\begin{tabular}{lcccc}
\hline & $(1)$ & $(2)$ & $(3)$ & $(4)$ \\
Tenure (years) & $-0.016^{* * *}$ & $-0.004^{* * *}$ & $-0.002^{* * *}$ & $-0.003^{* * *}$ \\
Tenure (years) $\times$ Sweden & $(0.0001)$ & $(0.0002)$ & $(0.0002)$ & $(0.0003)$ \\
& $-0.002^{* * *}$ & $0.0005^{* * *}$ & $0.001 * * *$ & $0.002 * * *$ \\
& $(0.0001)$ & $(0.0003)$ & $(0.0003)$ & $(0.0003)$
\end{tabular}




\begin{tabular}{|c|c|c|c|c|}
\hline Seniority & & $\begin{array}{c}-0.182^{* * *} \\
(0.003)\end{array}$ & $\begin{array}{c}-0.142^{* * *} \\
(0.003)\end{array}$ & $\begin{array}{c}-0.148^{* * *} \\
(0.004)\end{array}$ \\
\hline Seniority $\times$ Sweden & & $\begin{array}{c}-0.009 * * \\
(0.004)\end{array}$ & $\begin{array}{c}-0.017 * * * \\
(0.004)\end{array}$ & $\begin{array}{c}-0.020 * * * \\
(0.004)\end{array}$ \\
\hline Sweden $\times$ age group (18-29) & & & $\begin{array}{c}0.004 * * \\
(0.002)\end{array}$ & $\begin{array}{c}0.006^{* * *} \\
(0.002)\end{array}$ \\
\hline Sweden $\times$ age group (50-64) & & & $\begin{array}{c}-0.029 * * * \\
(0.002)\end{array}$ & $\begin{array}{c}-0.029 * * * \\
(0.002)\end{array}$ \\
\hline Common firm effects & $\mathrm{X}$ & $\mathrm{X}$ & $\mathrm{X}$ & $X$ \\
\hline Age group effects & & & $\mathrm{X}$ & $\mathrm{X}$ \\
\hline $\begin{array}{l}\text { Country indicator (Sweden) } \times \text { year } \\
\text { effects } \\
\text { Excluding those who are } 60+\end{array}$ & $\mathrm{X}$ & $\mathrm{X}$ & $\mathrm{X}$ & $\begin{array}{l}X \\
X\end{array}$ \\
\hline $\mathrm{N}$ & 1918300 & 1918300 & 1918300 & 1837676 \\
\hline
\end{tabular}

Notes: Seniority is measured as the decile the worker belongs to when ranked according to tenure within the firm. Estimation period 2000-2010. Reference age group is 30-49 in Columns 3-4. Heteroskedasticity-robust standard errors are reported in parentheses: ${ }^{* * *} \mathrm{p}<0.01,{ }^{* *} \mathrm{p}<0.05$, and ${ }^{*} \mathrm{p}<0.1$.

\subsection{Worker exits by tenure and seniority in expanding vs. shrinking firms}

To identify the effects of seniority rules, we next proceed to examine worker exits separately in expanding or stable and in shrinking firms. This setting is interesting because seniority rules should have more 'bite' in firms that need to reduce workers. We therefore split the data to firms where employment increases by more than $10 \%$ compared to the previous year, where employment declines by more than $10 \%$, and to firms where employment stays within $10 \%$ of the previous year. As there were no notable differences between the stable and the expanding firms we have combined these groups and compare the patterns in these firms to the shrinking firms. 
In Figures 4 and 5 we report the effects of tenure and seniority on the exit rates. The estimates plotted in the figure are based on a linear regression model where the exit rates are explained by the firm effects and year, age, tenure and seniority - all interacted with the country effect. Age effects are controlled by using indicators for ten-year age intervals allowing nonlinear patterns. The effects of tenure and seniority on worker exit rates are also unlikely to be linear. For this reason, we use indicators for each possible level of tenure and model the effect of seniority by adding indicators for each decile of within-firm seniority. To facilitate interpretation of the seniority profiles, the estimates are normalized to median seniority in the figures. The upper panels of Figures 4-5 show the estimated profiles, and the lower panels document the differences in the profiles between the Swedish and Finnish units. To assess the statistical significance of the differences, we provide conservative confidence intervals for the estimates by clustering at the common firm identifier level.

Figure 4. Effect of tenure and seniority on exit rates

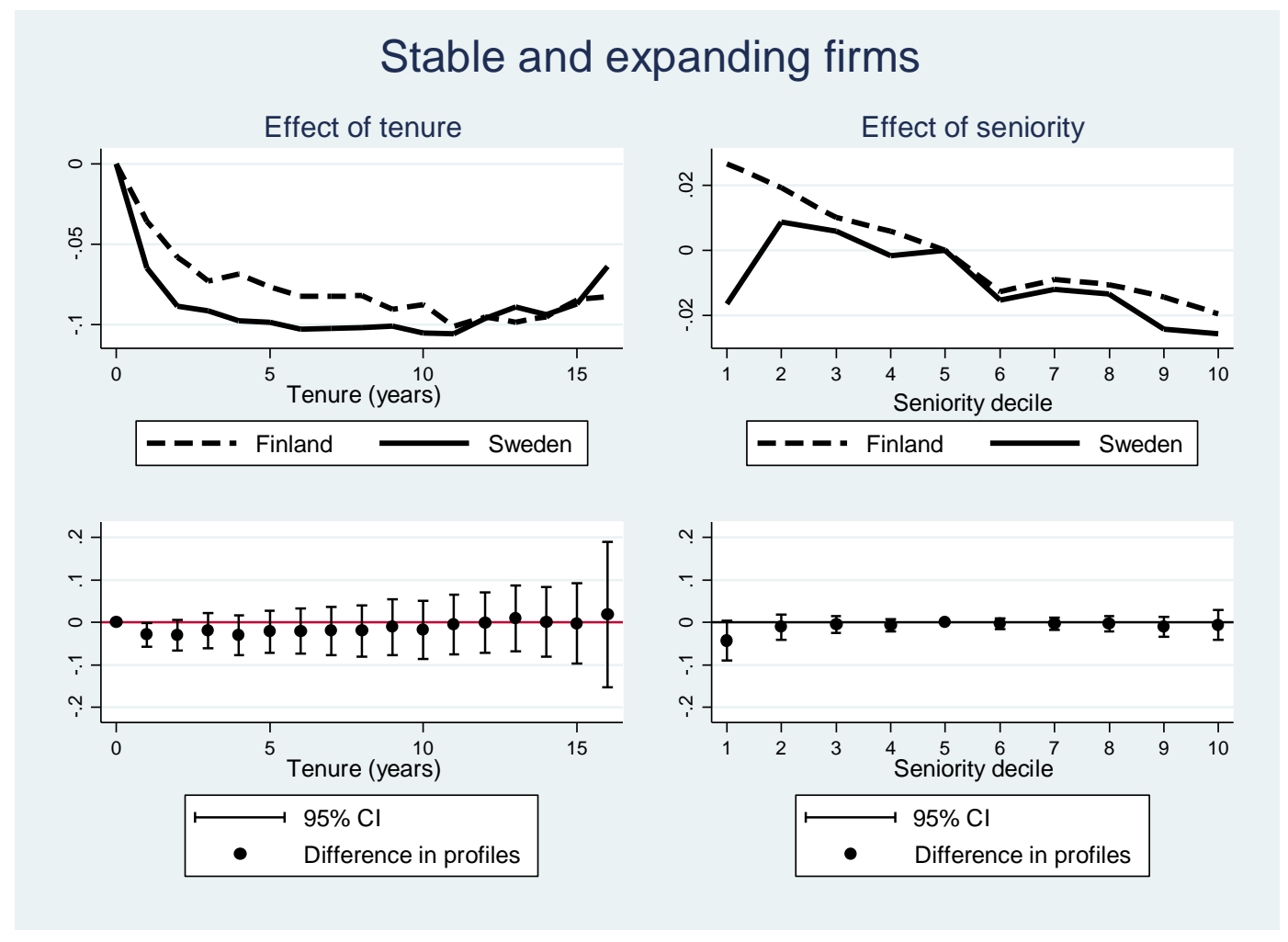

Notes: Stable and expanding firms are defined based on employment growth, as described in the text. The 95\% confidence intervals are indicated. 
Figure 5. Effect of tenure and seniority on exit rates, shrinking firms.

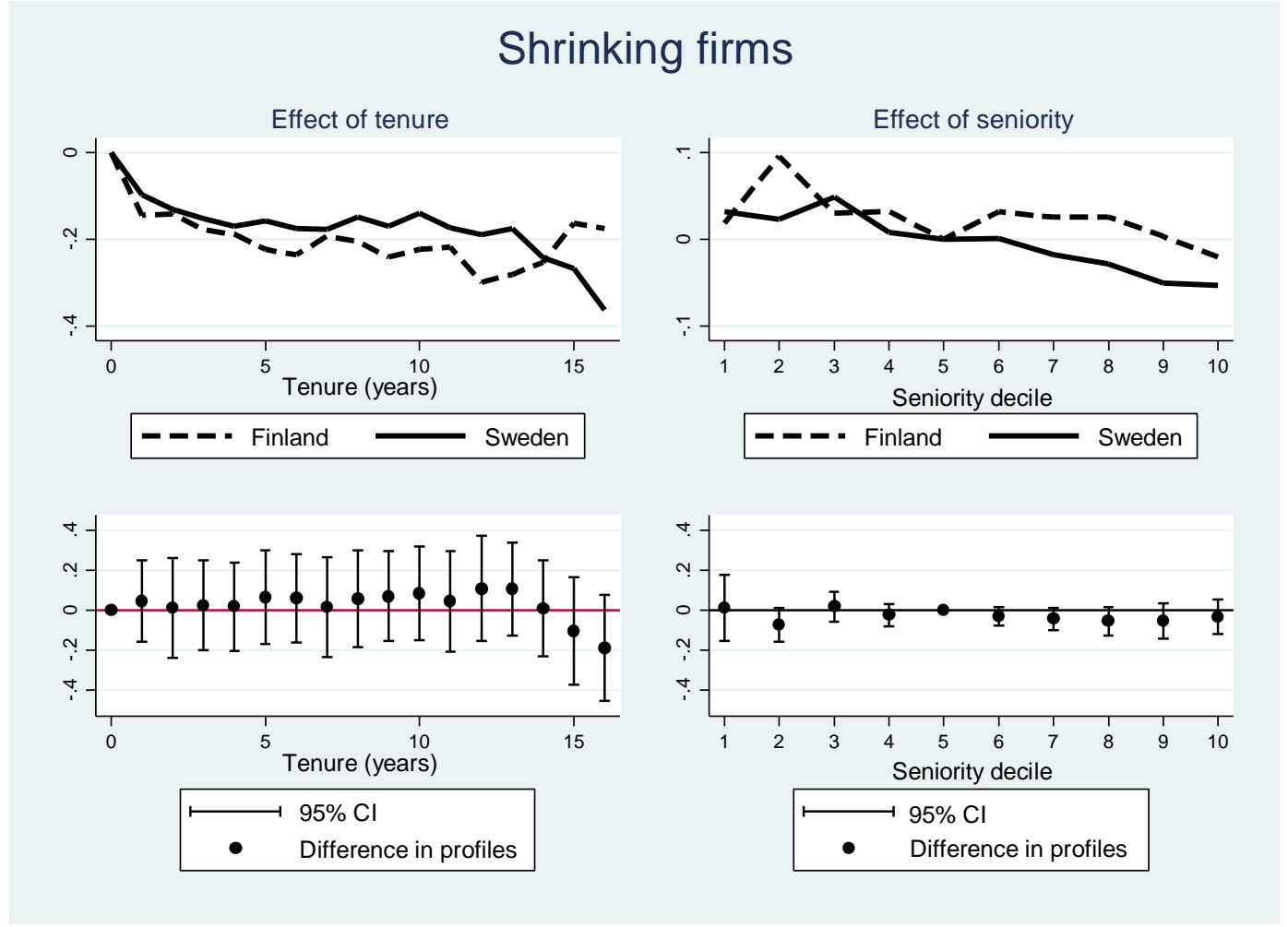

Notes: Shrinking firms are defined based on employment growth, as described in the text. The 95\% confidence intervals are indicated.

We find that the worker exit rates are generally much lower for those workers with longer tenure and higher seniority in both Sweden and Finland (Figures 4-5). This pattern that applies to expanding and shrinking firms is consistent with the estimation results in Table 4.

Regarding the cross-country differences in the effects of tenure and seniority we find some indications that seniority rules affect exit rates in the shrinking firms. Increasing tenure has a monotonously decreasing effect on the exit rates in Sweden while in Finland the pattern is somewhat U-shaped so that the workers with highest tenure are relatively more likely to exit in Finland. Also the effect of seniority is slightly different. An increase in seniority decreases the exit rates more in the Swedish units than in the Finnish units of the same firms. However, with clustered standard errors these differences are not statistically significant. 


\subsection{Effects on seniority-wage profile}

To examine the effects of seniority rules on wage formation, we estimate a set of regressionadjusted seniority-wage profiles. We use the logarithm of the standardized measure of total (hourly) wages that are trimmed at the $1^{\text {st }}$ and $99^{\text {th }}$ percentiles. We estimate the profiles for the full-time blue- and white-collar workers that have a weekly working time of 30-45 hours. Seniority is calculated separately for blue-collar and white-collar workers. To allow for the nonlinear effects of seniority on wages, we use indicators for each decile of seniority as in Figures 4-5.

The regression-adjusted seniority-wage profiles are based on regression models that account for the worker-firm (i.e., spell-specific) fixed effects, country and year. ${ }^{6}$ Tenure and age are controlled for non-parametrically and their effects are allowed to vary across county. Note that the effect of seniority is identified even after controlling for the effects of tenure and including spell-specific fixed effects because seniority is affected also by the tenure distribution among other workers in the firm (see Buhai et al., 2014). Standard errors are clustered at the firm level.

We find higher returns to seniority for above-median-seniority workers in Sweden (Figure 6). This pattern is consistent with seniority rules increasing the relative individual-level bargaining power of older workers in the Swedish units of multinational firms. The pattern remains intact if we estimate the seniority-wage profiles only for those who are younger than 55.

Importantly, the regression-adjusted seniority-wage profiles differ significantly for blue- and white-collar workers (Figure 7). ${ }^{7}$ Swedish blue-collar workers earn a substantial and robust seniority wage premium while seniority has no effect on wages in Finland beyond the lowest decile. For the white-collar workers the seniority wage profiles are more similar, the only notable difference occurring at the lower tail of the seniority distribution. Available evidence suggests that this is probably due to higher minimum wages in Sweden. For example, in construction, retail and the hotels and restaurant sector, the union-bargained minimum wages

\footnotetext{
${ }^{6}$ Buhai et al. (2014) also estimate models that account for spell-specific fixed effects.

${ }^{7}$ There is a larger fraction of white-collar workers in Sweden compared to Finland due to the location of headquarters of Swedish multinational firms.
} 
are approximately 10 percentage points higher, relative to the average manufacturing wage for production workers, in Sweden than in Finland (Skedinger, 2010b). ${ }^{8}$

Figure 6. Regression-adjusted seniority-wage profiles for all workers.

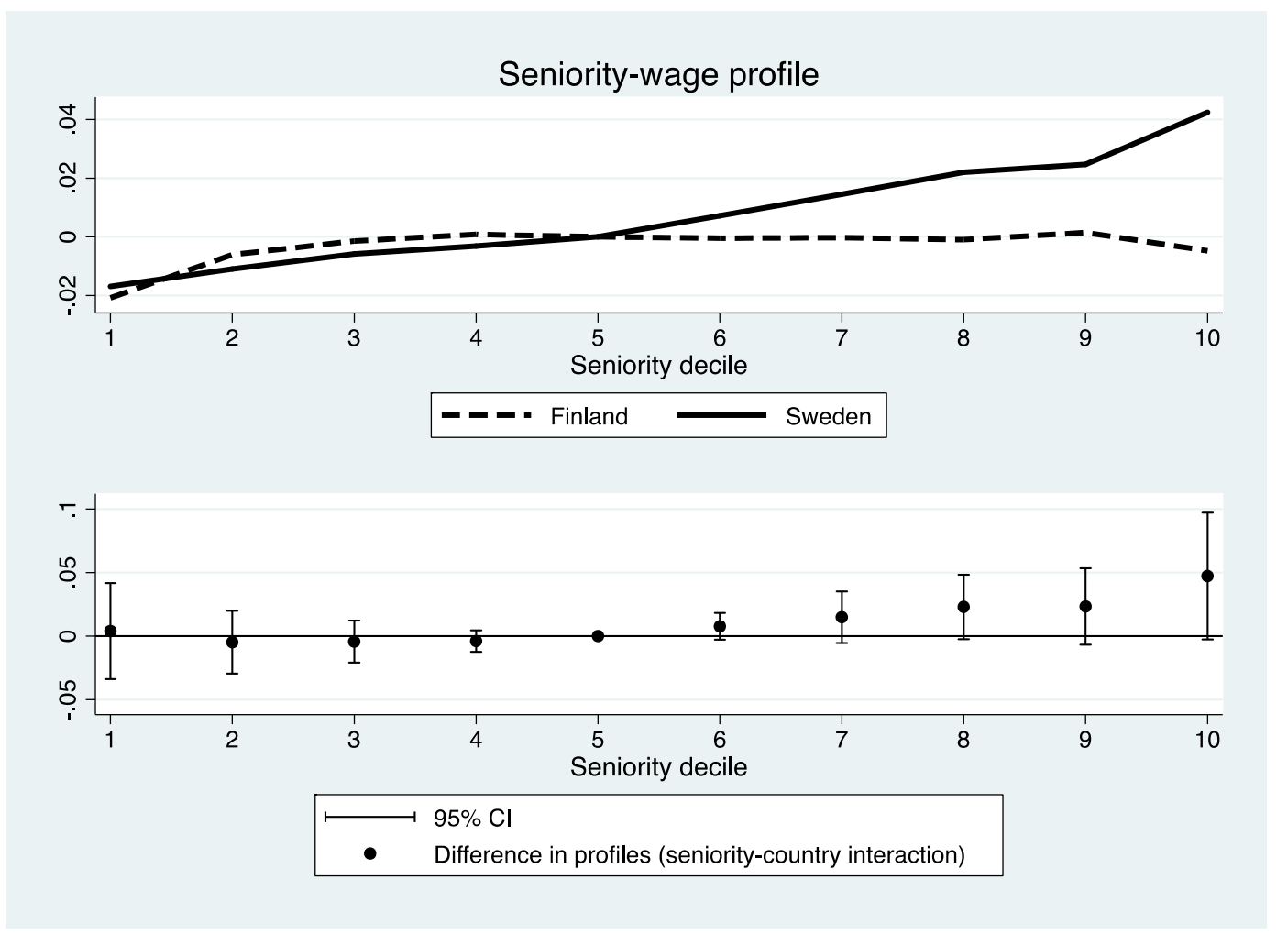

Notes: The 95\% confidence intervals are indicated.

\footnotetext{
${ }^{8}$ For 20-year-old unskilled workers with no previous experience, the minimum wage bite in Sweden and Finland, thus calculated, amounted to $50 \%$ and $40 \%$, respectively, in construction, $56 \%$ and $44 \%$, respectively, in retail, and 55\% and 44\%, respectively in hotels and restaurants, in 2006.
} 
Figure 7. Regression-adjusted seniority-wage profiles for white- and blue-collar workers.
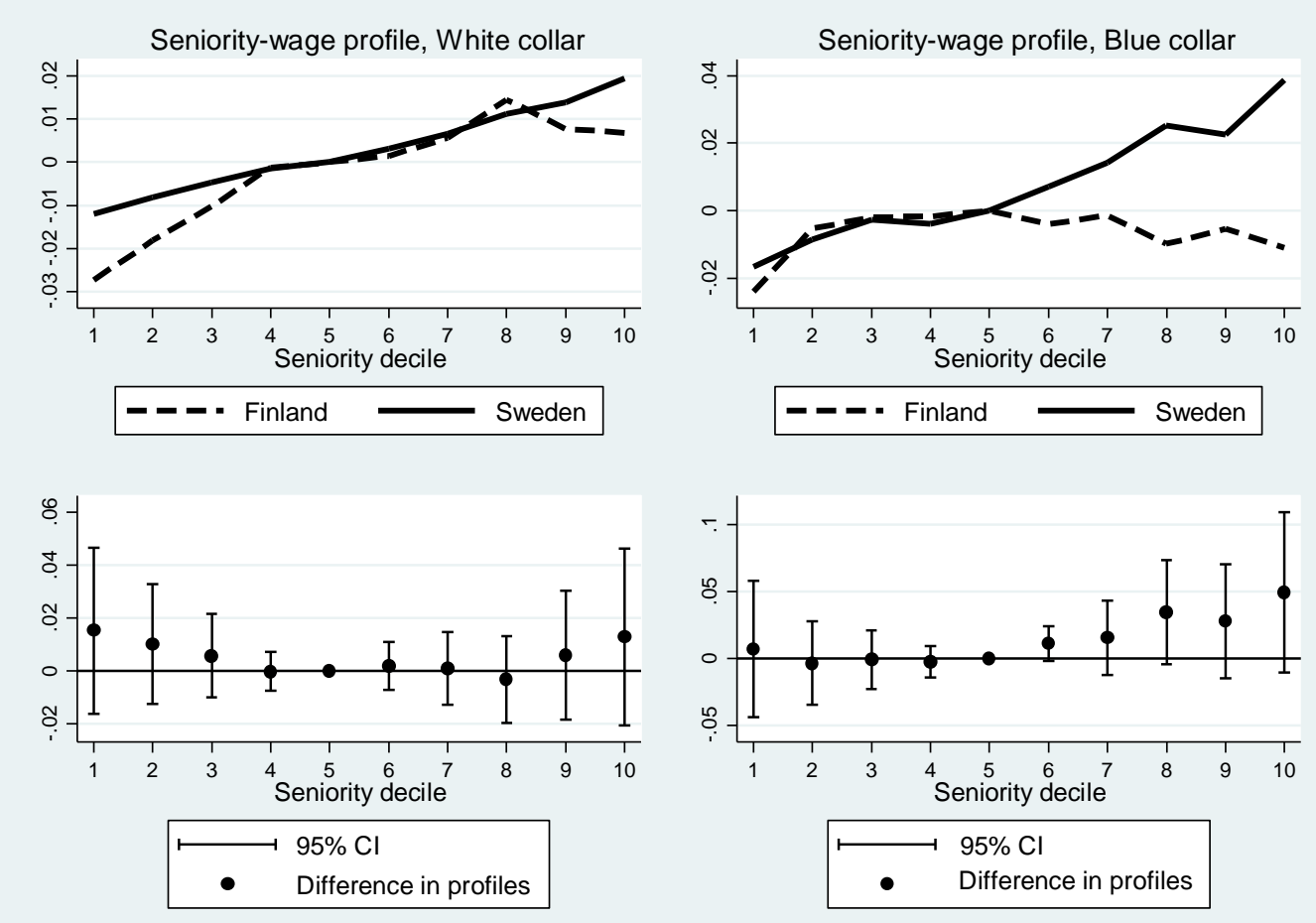

Notes: The 95\% confidence intervals are indicated.

\section{Conclusions}

The effects of institutions are challenging to analyze with standard cross-country data because countries are very difficult to make fully comparable. On the other hand, single-country studies tend to suffer from relatively minor variation in these institutions and from external effects, as it is seldom possible to exclude the possibility that reforms targeted to specific groups or firms also affect others indirectly.

We shed fresh light on the workings of labor market institutions by creating a novel type of international data. It is the first-ever effort to create a multi-country linked employeremployee data set with firms matched across countries. The data contain information on workers and firms in matched firms operating in two countries, Finland and Sweden. Therefore, it is possible to identify workers in the respective countries who share a common employer. While our research focused on the specific effects of seniority rules, the new type 
of multi-country linked employer-employee data that we constructed also holds promise for studies examining other key labor market institutions and their impacts.

Seniority rules, which are firmly specified by law in Sweden but not in Finland, stipulate that employees be laid off in inverse order of seniority when firms dismiss workers for economic reasons. Our results show that seniority rules have effects on worker mobility and wages. Seniority rules protect the oldest workers against dismissals. The exit rates of older, more senior workers are significantly smaller in a country with tighter seniority rules. The effect of seniority rules on worker exit is more pronounced in shrinking firms. We also document that seniority rules cause steeper seniority-wage profiles, which is consistent with increased bargaining power for those who have stayed with the same firm for longer. 


\section{References}

Autor, D.H., Kerr, W.R. and Kugler, A.D. (2007), Does employment protection reduce productivity? Evidence from U.S. states, Economic Journal 117, F189-F217.

von Below, D. and Skogman Thoursie, P. (2010), Last-in first-out? Estimating the effect of seniority rules in Sweden, Labour Economics 17, 987-997.

Bergström, O. (2011), Regler vid driftsinskränkningar i viktiga konkurrentländer, in Rudeberg, S. and Hedlund, H., Faktiska konsekvenser av turordningsregler i LAS och kollektivavtal, Confederation of Swedish Enterprise and the Swedish Federation of Salaried Employees in Industry and Services, Stockholm.

Boeri, T. and Jimeno, J.F. (2005), The effects of employment protection: Learning from variable enforcement, European Economic Review 49, 2057-2077.

Boeri, T. and Van Ours, J. (2013), The economics of imperfect labor markets. Princeton: Princeton University Press.

Buhai, I.S., Portela, M.A., Teulings, C.N. and van Vuuren, A. (2014), Returns to tenure or seniority?, Econometrica 82, 705-730.

Burgess, S., Knetter, M. and Michelacci, C. (2000), Employment and output adjustment in the OECD: A disaggregate analysis of the role of job security provisions, Economica 67, 419435.

Centeno, M. and Novo, A.A. (2014), Paying for others' protection: Causal evidence on wages in a two-tier system, Discussion Paper No 8702, IZA, Bonn.

Confederation of Swedish Enterprise (2012), Slutsatser ur de partsgemensamma rapporterna om faktiska konsekvenser av LAS turordningsregler, Confederation of Swedish Enterprise, Stockholm. 
Haltiwanger, J., Scarpetta, S. and Schweiger, H. (2006), Assessing job flows across countries: The role of industry, firm size and regulations, Discussion Paper 2450, IZA, Bonn.

Jovanovic, B. (1979), Job matching and the theory of turnover, Journal of Political Economy 87, 972-990.

Kahn, L.M. (2007), The impact of employment protection mandates on demographic temporary employment patterns: International microeconomic evidence, Economic Journal 117, F333-356.

Kugler, A.D. (2004), The effect of job security regulations on labor market flexibility: Evidence from the Colombian labor market reform, in Heckman, J. and Pagés, C. (eds.), Law and employment: Lessons from Latin America and the Caribbean, NBER Conference Report series. Chicago and London: University of Chicago Press.

Kugler, A. and Pica, G. (2008), Effects of employment protection on worker and job flows: Evidence from the 1990 Italian reform, Labour Economics 15, 78-95.

Lafontaine, F. and Sivadasan, J. (2009), Do labor market rigidities have microeconomic effects? Evidence from within the firm, American Economic Journal: Applied Economics 1, 88-127.

Larsson, H., Larsson, S., Oscarsson, E. and Maier Söderberg, L. (2013), LAS i förändring ett kunskapsunderlag om anställningsskydd, kompetens och omställning. Stockholm: Swedish Confederation of Professional Associations.

Lazear, E.P. (1979), Why is there mandatory retirement? Journal of Political Economy 87, 1261-1284.

Lazear, E. (1990), Job security provisions and employment, Quarterly Journal of Economics 105, 699-726.

Leonardi, M. and Pica, G. (2013), Who pays for it? The heterogeneous wage effects of employment protection legislation. Economic Journal 123, 1236-1278. 
Lindbeck, A. and Snower, D.J. (2001), Insiders versus outsiders. Journal of Economic Perspectives 15, 165-188.

Martins, P. (2009), Dismissals for cause: The difference that just eight paragraphs can make, Journal of Labor Economics 27, 257-279.

Messina, J. and Vallanti, G. (2007), Job flow dynamics and firing restrictions: Evidence from Europe, Economic Journal 117, F279-F301.

Nickell, S. and Layard, R. (1999), Labor market institutions and economic performance, in Ashenfelter, O. and Card, D. (eds.), Handbook of labor cconomics, Volume 3, Amsterdam: Elsevier Science, North Holland.

OECD (2013), Education at a glance, Paris.

Skedinger, P. (2010a), Employment protection legislation: evolution, effects, winners and losers. Edward Elgar, Cheltenham, UK, and Northampton, MA, US.

Skedinger, P. (2010b), Sweden: A minimum wage model in need of modification, in Vaughan-Whitehead, D. (ed.), The minimum wage revisited in the enlarged EU, Edward Elgar, Cheltenham, UK, and Northampton, MA, US, and ILO, Geneva.

Tuominen, E. (2013), Flexible retirement age in Finland. The evaluation of the Finnish flexible retirement scheme in light of employer and employee surveys. Working Paper No. 03/2013, Finnish Centre for Pensions,.

van der Wiel, K. (2010), Better protected, better paid: Evidence on how employment protection affects wages, Labour Economics 17, 16-26.

World Bank (2015), Doing business 2016, Washington D.C. 
Appendix Figure A1. Firm growth in the linked data.

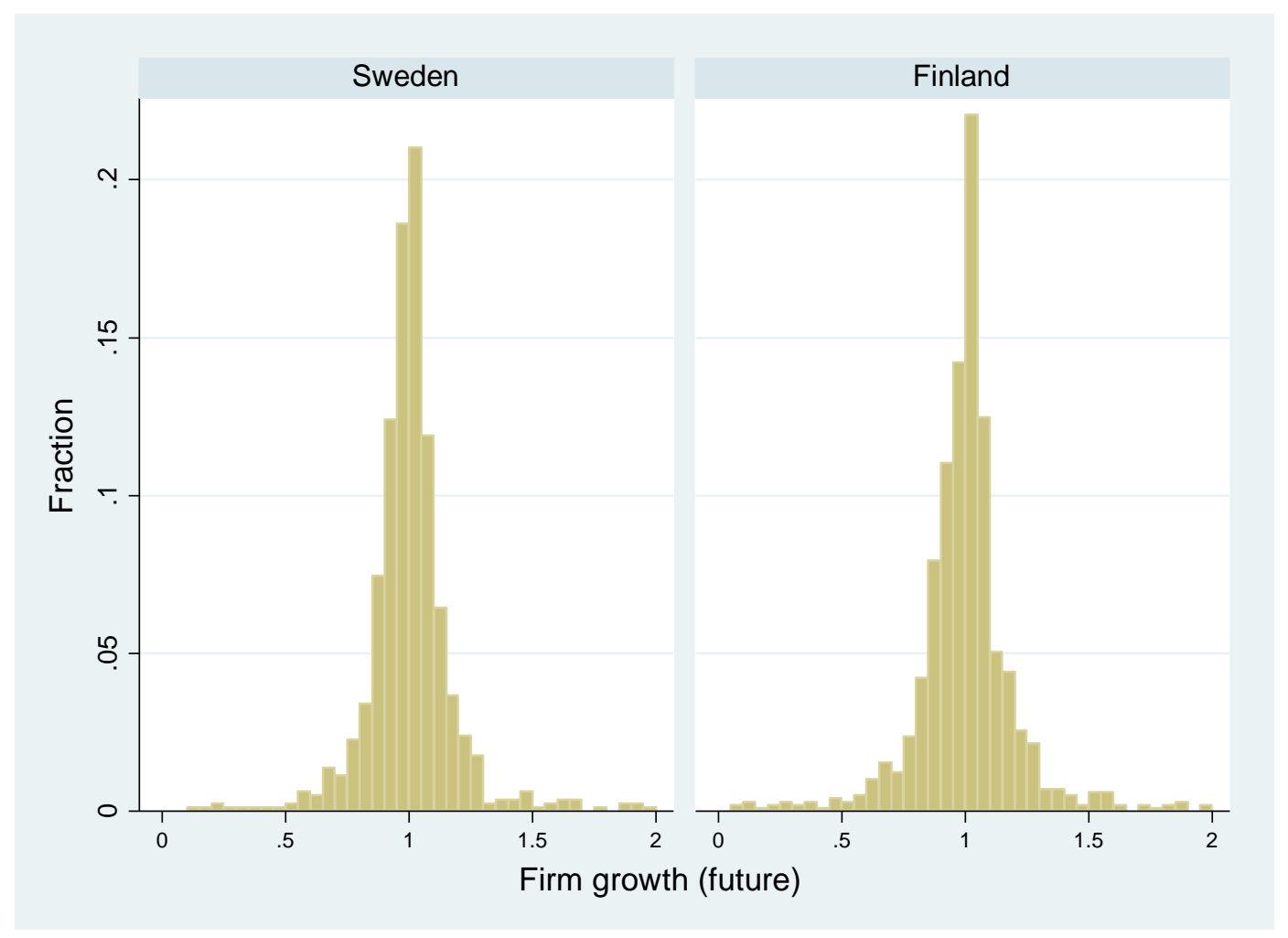

Notes: Definition of firm growth: number of workers in firm in year $\mathrm{t}+1$ / number of workers in year $\mathrm{t}$. 
Appendix Figure A2. The correlation between imputed tenure and observed tenure in the Finnish data.

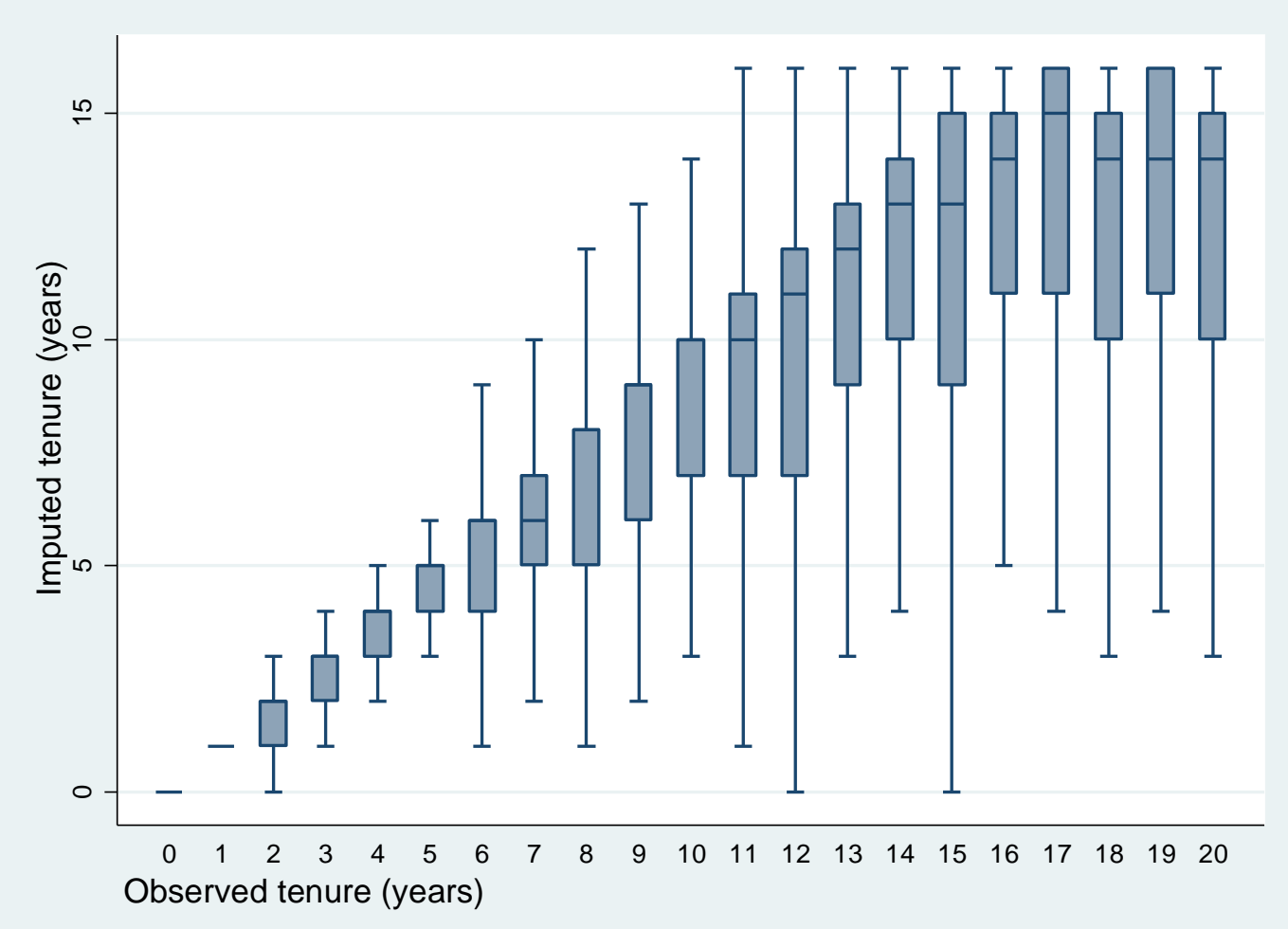

Notes: Upper and lower quartile and minimum, maximum and median values are marked. 
Appendix Table A1. Determinants of worker entry at the firm level.

\begin{tabular}{lccc}
\hline & $(1)$ & $(2)$ & $(3)$ \\
\hline Country indicator (Sweden) & $0.046^{* * *}$ & $0.046^{* * *}$ & $0.034^{* * *}$ \\
& $(0.009)$ & $(0.009)$ & $(0.007)$ \\
Age group (18-29) & & & \\
Age group (50-64) & $0.239^{* * *}$ & $0.225^{* * *}$ & $0.228^{* * *}$ \\
& $(0.008)$ & $(0.008)$ & $(0.010)$ \\
Sweden $\times$ age group (18-29) & $-0.057^{* * *}$ & $-0.051^{* * *}$ & $-0.054^{* * *}$ \\
& $(0.007)$ & $(0.006)$ & $(0.007)$ \\
Sweden $\times$ age group (50-64) & -0.005 & -0.016 & -0.001 \\
& $(0.013)$ & $(0.011)$ & $(0.013)$ \\
& -0.005 & -0.009 & -0.013 \\
Common firm effects & $(0.013)$ & $(0.012)$ & $(0.010)$ \\
Common year effects & & & \\
\hline Estimation period & & $\mathrm{X}$ & $\mathrm{X}$ \\
$\mathrm{N}$ & $2000-2011$ & $\mathrm{X}$ & $\mathrm{X}$ \\
\hline
\end{tabular}

Notes: Reference age group is 30-49. All regressions are weighted by firm size. Heteroskedasticity-robust standard errors are reported in parentheses: ${ }^{* * *} \mathrm{p}<0.01,{ }^{* *} \mathrm{p}<0.05$, and ${ }^{*} \mathrm{p}<0.1$. 